\title{
Variations of magnesium isotopic composition in tissues and plasma of obese versus lean minipigs
}

\author{
SAMUEL LE GOFF ${ }^{1}$, JEAN-PHILIPPE GODIN ${ }^{2}$, JOSE M. \\ RAMOS NIEVES $^{2}$, EMMANUELLE ALBALAT ${ }^{3}$ AND \\ VINCENT BALTER ${ }^{1}$ \\ ${ }^{1}$ ENS de Lyon, Univ Lyon 1, CNRS UMR 5276, LGL-TPE \\ ${ }^{2}$ Nestlé Research \\ ${ }^{3}$ Laboratoire de géologie de Lyon UMR 5276, ENS et Université \\ Lyon 1 \\ Presenting Author: samuel.le-goff@ens-lyon.fr
}

Magnesium $(\mathrm{Mg})$ is a bio-essential element involved in many physiological processes. It is the second most abundant intracellular cation and the fourth most abundant metal in the human body. $\mathrm{Mg}$ deficiency has been shown to be associated with type 2 diabetes (T2D) [1]. The availability of $\mathrm{Mg}^{2+}$ is of major importance for the regulation of many enzymes involved in glucose metabolism, which could explain its role in T2D [2]. The contribution of measuring the isotopic composition of $\mathrm{Mg}$ in relation to serum concentrations was demonstrated by Grigoryan et al. in 2019 [3] to diagnose diabetic individuals from healthy people.

We measured the $\mathrm{Mg}$ isotopic composition $\left(\delta^{26} \mathrm{Mg}\right)$ by multiple collector- inductively coupled plasma-mass spectrometry in different organs (i.e. liver, kidney, heart, muscle and bone) and plasma of obese and lean minipigs to investigate the amplitude of isotopic fractionation between these two phenotypes and possibly elucidate the mechanisms leading to $\mathrm{Mg}$ isotopic fractionation.

$\mathrm{A}{ }^{24} \mathrm{Mg}$ enrichment in all the organs of obese specimens compared to control animals is observed. In addition, the $\mathrm{Mg}$ isotope compositions were significantly associated with several blood parameters (i.e. glucose level and hyperglycemic clamps data) used to describe glucose homeostasis. The results highlight the possible loss of intracellular isotopic $\mathrm{Mg}$ distribution in obese minipigs. These data shed light on a new example of isotopic fractionation in biological system and the importance to continue exploring this field to better understand the cause and consequences of such process.

\section{References:}

[1] Wang, Shaw, Yeh, Kao (2005). Asia Pacific journal of clinical nutrition 14(3), 263-269

[2] De Baaij, Hoenderop, Bindels (2015). Physiological Reviews 95(1), 1-46.

[3] Grigoryan, Costas-Rodríguez, Van Laecke, Speeckaert, Lapauw, Vanhaecke. (2019). J Anal At Spectrom 34(7), 1514 1521. 